\title{
Establishing, maintaining, and evaluating an interviewer training program
}

\author{
ALLEN J. SCHUH \\ School of Business and Economics, California State University, Hayward, California 94542
}

\begin{abstract}
This article summarizes the author's impressions on how to train employment interviewers. The research literature is summarized. The linkages between performance evaluation and selection interviewing are specified. Employment interviews can become more reliable and possibly even valid if the interviewers receive training in question asking, listening, decision making, and rating.
\end{abstract}

It might appear foolhardy for anyone with even a passing acquaintance with the relevant research literature on the selection interview to suggest that interview impressions might be capable of correlating with job success. But, let us realize that if interviewers are trained in how to avoid errors in asking questions, listening, decision making, and rater bias, then the interrater variability should diminish and the result should be higher interrater reliability coefficients. An additional boost in reliability might be possible if there were aids for conducting the interview and recording the evaluation. If the method of gathering the confirming information can be standardized and the method of recording interview impressions can be refined in content and style, then there should be an increase in interrater reliability. High interrater reliability is an essential step to demonstrating predictive validity for the interview. If training is a good thing for the interviewer and if a structured interview format and well prepared rating form are necessary for interrater reliability for the predictor, then why is not the same true for the criterion?

The nature of the criterion measure should receive our attention. Both the type of criterion that is legitimate to validate the interview impressions and criterion collection should be considered. The keystone that will support claims of predictive validity for the selection interview may well rest on these judgments.

\section{RELEVANT RESEARCH}

No one knows for sure how many people might, with instruction, be successful employment interviewers (Dictionary of Occupational Titles, 1965, Code 166.268). Wonderlic (1942) reported training several thousand interviewers and, based on experience, suggested four general qualifications: good conversational ability, good mental ability, a keen sense of humor, and a pleasing appearance. In addition, four specific characteristics were thought desirable: interest in and curiosity about people, ability to show sympathetic understanding and yet to remain intelligent and alert to the realities of the situation, acquaintance with life in a few of its less pleasant aspects, and adaptability to social situations.
Uhrbrock (1948) recommended that the beginning interviewer should be "broken in" by conducting different kinds of interviews. The trainee should be assigned to exit interviewing, then to surveys of employees' attitudes by means of conversational interviews, and finally to employment interviewing. This order placed employment interviewing in the most important position and utilized the others as a preparation. By interviewing those who are leaving their work, the interviewer finds out some of the reasons for failure and dissatisfaction. In attitude surveys, the importance of certain attitudes and the differences between good and bad ones are discovered. The trainee will then know some particular attitudes that should be watched for in prospective employees.

Bellows and Estep (1954) established four requirements for interviewer training. Interviewers should be aware of the errors that can exist in the appraisal of applicants. They should realize the necessity of maintaining an objective point of view. They should be familiar with the results of scholarly research in this area. They should develop, evaluate, and apply objective methods such as item analysis for specific interview situations. Training of interviewers should also include the acquisition of job information and job knowledge, training in company policy, training in how to converse, and training in the use of language in questioning.

Kahn and Cannell (1957) reported that the purpose of their chapter on learning to interview was to give the reader an opportunity to identify good interviewing techniques. Their goal was to increase the trainee's probability of being perceived as within the communication range. The components of this behavior are identified as permissiveness, receptivity, and empathy. Successful interviewers are effective because they have learned to create the psychological atmosphere in which respondent communication flourishes. The essential quality required to establish such an atmosphere is a sensitivity to human relationships, especially those relationships characteristic of the interview. Kahn and Cannell reported that sensitivity can be developed through appropriate training, and they suggested that such training gives the learner an opportunity to discuss 
interviewing principles, to practice interviews, to describe his own successes and failures, and to discuss the interviewing experiences of others in an environment in which he feels secure.

Despite all of this speculation, there have been only a few relevant research reports on the effects of a specified sequence of experiences or training on interviewer impressions of applicants in an employment setting. The first attempt to investigate the effects of a specific training program found that interviewers would indeed be less likely to commit the halo error after even a brief (3-h) course that focused on errors in asking questions and in decision making (Schuh, 1971).

A more recent report demonstrated that even a brief experience (again, several hours) at rating extended over several weeks produced evaluations different from those produced by a no-experience condition (Schuh, 1973). A carefully constructed rating form developed in earlier research (Hakel \& Schuh, 1971) was able to produce the same evaluations as the structured experience did. Thus, rating aids can substitute for training or structured and focused experience.

\section{THE INTERACTION PROCESS}

The interview is a communication or interaction process in which two people try to interact with each other and each actively accepts or rejects interaction attempts. In that process lie the strengths and the weaknesses of the interview as an information gathering and confirming technique. If the interaction is handled properly, the interview becomes a powerful technique capable of (1) obtaining access to material otherwise unobtainable, such as the applicant's motivation for the job, personal qualities, and ability to get along on the company team, and (2) using recruiting appeals persuasively.

If improperly handled, interview interaction can become a serious source of bias and result in a restriction or distortion of communication flow. Therefore, it is necessary that the interviewers learn to control the interaction with the respondents so that the selection track can be maintained and the purposes of the interview can be achieved. In controlling interaction, it is possible that the interviewer could conduct the interview in a manner that would allow the applicant to distort or withhold information. It is also possible that the applicant is not able to produce relevant information because of interfering and irrelevant behaviors on the part of the interviewer, who does not understand that the behaviors are interfering with the communication process. The interviewer is the one who should be in control of the interview, and the major means of eliciting information is by asking questions. The questions asked (their order, wording, and emphasis) can be an obstruction to communication. The specific techniques that the interviewer used may be another possible source of obstruction. It is possible that the techniques the interviewer utilizes are not functional as intended.
The interviewer may think that one should "sell" the applicant on working with the company before evaluation, or that sensitive areas such as financial, health, or criminal records should be avoided, even though the information is needed for bonding.

\section{THE EVALUATION PROCESS}

\section{The Model of the Interview Evaluation Process}

Probably, the best theoretical treatment of the interview evaluation process was by Wherry (Note 1 ), who outlined the contribution of the several contaminants to the overall suitability evaluation. Wherry suggested that the evaluation process is predominantly one of recall on the part of the rater. The material of recall is a sum of the totality of pertinent observations of the appropriate behaviors of the applicant. If the interview evaluation is to reflect the true score of the applicant, the behavior observed in the interview must have been an adequate reflection of the applicant's behavior. Thus, the accuracy of the rating depends upon the following steps chronologically: (1) relevant behavior by the applicant in the interview setting, (2) observation of the performance by the interviewer, and (3) recall at the time of evaluation of the observations by the interviewer. The adequacy of the evaluation is based upon the adequacy of these three processes. Wherry's equation suggested that the final overall suitability judgment tells us a good deal about the interviewer. The evaluation will contain a true score, a specific bias, an overall bias, environmental influence, and several other sources of error. The major contribution of Wherry's paper has been to suggest the points of focus in interviewer behavior that are the major threats to validity. Wherry leaves little doubt that evaluation forms should be highly structured, so raters can focus their attention on relevant and measurable aspects of performance. Interviewers should try to become aware of their biases and should record specifically observed behavior to improve objectivity of recall. Adding extra qualified raters, each with a completely different set of contacts with the ratee, will cancel specific and overall bias and error. Thus, slight variations in interview procedure, such as adding additional qualified evaluators to the screening process and carefully structuring the evaluation forms, may preclude the necessity for a good deal of training. Also, relevant applicant behavior is more likely to be shown in the interview if the applicant is given a work sample to perform and if the questions for the interview are structured. Interviewers need to be taught how to get right into the interview and not tell too much about the job until the evaluation stage is over. Interviewers need to know how to ask relevant questions, one at a time, which do not lead the applicant, and how to maintain control over the interview. Because interviews are so brief a period of observation, it is likely that most interview evaluations contain a good deal of error. Interviewers should be taught how to read the required questions the same way to all applicants and to stress generally accepted good speech behavior such as greater and steady intensity, careful enunciation, longer syllable duration, few pauses, and greater variety of pitch and pattern of fundamental vocal frequency, and to stretch the syllables out a bit. Interviewers should also be taught which forms of nonverbal cues can give false impressions; indeed, most nonverbal forms of behavior add only error to evaluation.

To insure that interviewers observe the applicant behaviors, interviewers should be taught exactly what to look for in the applicant's behavior and how to know what critical implications these behaviors have for later job behaviors. Interviewers need to learn methods of listening accuracy, arranging the setting for comfortable communication, maintaining attention, and taking notes. The many possible errors in listening accuracy and decision making, such as gating (Bruner, 1957), order and contrast effects, effects of stereotypes (Webster, 1964), and the logical errors of non sequiturs and begging the question, should be reviewed. 
At the time of final evaluation, when the interviewer bases the final overall suitability judgment on recall, the interviewer needs every possible memory aid and needs to be aware of rating errors: leniency, central tendency, and halo errors.

If one hopes to maximize both effectiveness and efficiency (reaching the goal and doing it at least cost), one might suggest several other procedures that would greatly lessen demands on the interviewers. Organizations should use systematic interview and performance evaluation forms (and they should be the same), there should be a systematic approach to resumé screening, references should only be used to check dates of employment, and everyone should be paid $25 \%$ more than he can make anywhere else (to cut turnover to almost zero). Many approaches to improving the interview performance evaluation process should have more effect if used together than if only little changes are made over time.

\section{Is It Worth Training Managers to Interview?}

The author suspects that most educators would agree in principle with the type of training recommended here for managers as well as for interviewers. The direct link between interviewing and performance evaluation is the rating model that fits both settings. If training is good for the interviewer, it is then also good for the manager.

Generally, most managements ask themselves three questions: (1) "What are the alternatives?", which presents a difficult problem of the calculation of the opportunity cost of training; (2) "How can we be sure the measured impact of training is due only to the effects of the training and not a contaminant?"; and (3) "Can I get a payback for the cost of training within 1 year?" Ultimately the utility of much of what is said here will be based on faith rather than proof.

\section{The Three Dimensions of a Good Training Program}

One dimension of the training program is off-the-job special study of material in a carefully selected reading list. Interviewers should read the reviews of interview research by Mayfield (1964), Spool (1978), Ulrich and Trumbo (1965), Wagner (1949), and Wright (1969). They should also be familiar with the material in Blum and Naylor (1968) and Cronbach (1970). It is absolutely essential that interviewers read the book by Webster (1964).

The second dimension is needed because interviewing is too difficult and important to learn only through reading. While the reading may help the learner to get an overall perspective on the problem and the process, reading can never replace on-the-job experience and practice under coaching. Coaching on the job excels in four of the five most important principles of learning: active participation of the learner, feedback of knowledge of results, opportunity for practice, and the stimulus-response conditions that transfer directly to the job (Bass \& Vaughan, 1966). The reading of the special study list provides the novice with the fifth important principle of learning: meaningful organization of the materials. The coaching program should probably use several different coaches. For the training, a minimum of 10 interviews should be scheduled. The novice should read about $10 \%$ of the material between each interview and should be carefully debriefed on both the reading material and his impressions of applicants interviewed.

The third dimension is discussion in groups of common interview problems. Whenever several new interviewers are being trained at the same time, they can be helped a good deal at the beginning by simple discussions covering such topics as "How long should an interview take?", "What should be done if applicants do not seem able to express themselves?", "What should be done if the interviewee talks off the subject and doesn't seem inclined to stop?", "How should one recruit the applicant with high qualifications?", "How should one present persuasive appeals to applicants?", and "How should one interview under a severe $(15-\mathrm{min})$ time constraint?" A good deal that is said in these discussions will probably have to be said over again in individual coaching, but the discussion may help by orienting the beginner and speeding up the learning process. The same can be said about readings on the interview. Reading may never take the place of practice under supervision, but it may prepare beginners to recognize situations and to catch on more rapidly when they encounter such situations in an actual interview.

The early orientation period is necessary to show the learners that they are going to acquire the skills of perceptual sensitivity, or an awareness of the interview mechanics that one does not see without concentrated study, and action flexibility, or an ability to see several alternative ways of handling the interview subprocess.

Discussion of interview problems can orient the beginner in the same way as coaching and individual reading assignments. One discussion procedure is to present a number of interview situations, one by one, and have them discussed. Negative situations abound and are intrinsically motivating because they arouse the beginner's interest by showing the difficulty of detecting characteristics they may not have given much thought to, such as job motivation. These simulated interviews can also indicate that some problems, such as the applicant's getting off the selection track, have more than one solution. If a patterned or organized interview is being used by the firm, some discussion of the pattern or method of organization should be given in the orientation period. After the beginner has been oriented by means of readings and discussion, the training can proceed with demonstrations, practice, and individual coaching. This succession of steps would be accepted by many as the proper order for interview training.

\section{Evaluation of the Setting}

No one should institute a training program of any kind unless he has evaluated the setting to be sure that programs started can be maintained and improved over time. One should do a maintainability check. This test should estimate the total effort in people, time, money, and materials necessary to keep the training program at an acceptable operating level.

A compatibility check is also needed. This test is to determine (1) the effect on the training program of personnel changes and (2) the impact of the interviewing training experience on the participating personnel in their other tasks besides employment interviewing.

Finally, a technical documentation evaluation is needed. This test is to determine the adequacy of the instruction manuals and other printed materials intended as aids. All instances in which these materials are vague or misleading should be noted so the program can be improved over time.

Unfortunately, the greatest contaminant in the whole setting is the applicant's future supervisor. Since the supervisor can make or break the employee regardless of the interviewer's effectiveness, it is a good practice for the interviewer to acknowledge that one hires for a supervisor and not for the whole organization. If the supervisor fails to provide careful feedback to the employee and to do a good job in general of supervising, such as giving problem solving instead of "tell-and-sell" reviews, the best interviewer faces a hopeless task.

Interviewer effectiveness tends to be judged by a comparison of what the interviewer said about the applicant during preemployment screening with what the supervisor says about the same applicant toward the end of a probationary period of work experience. Unfortunately, half of the problem, then, is the supervisor who will fill out the other evaluation. Unless that evaluation receives at least as much care as the interviewer's, it is going to be extremely difficult to demonstrate validity for the interview. Managers tend to assume that they are $100 \%$ correct in their evaluations. Thus, if an applicant receives a low rating, the supervisor wants to blame the employee and the interviewer who recommended hiring. There is a nasty habit among managements to assume that to question the assumption of $100 \%$ 
accuracy on the part of the supervisor is to threaten the entire command structure of the organization, and, therefore, it is not allowed, unfortunately. One needs only to be acquainted with the work of Whisler and Harper (1962) to see how off the mark the $100 \%$ accuracy assumption really is.

\section{Evaluation of the Interviewer}

Interviewers should make better hiring decisions after training than they would have without training. If there are large numbers of novices to be trained, one should use Campbell and Stanley's (1963) posttest-only control group design and test for a difference in effectiveness. Generally, a base rate of success in hiring is known, and one need only score better than the known rate to be effective. One of the best criterion to gauge interviewer effectiveness is a simple comparison between the number of applicants who make a satisfactory initial adjustment to their supervisor, task, and setting and those who do not, based on the interviewer's recommendations.

\section{Evaluation of the Total Program}

Ideally, the coaches should report that they are pleased with learner progress, the learners should report that they are pleased with their training, and the learners should make more accurate judgments of initial adjustment on the part of applicants.

\section{CONCLUSION}

Employment interviewers should receive training that utilizes on-the-job coaching and off-the-job special study. A traditional lecture-discussion format might also be used to generate learner interest and resolve differences of opinion. Whenever possible, learners should be provided aids for screening resumés, asking questions, and rating applicants. Any training given to the interviewers should also be provided to supervisors and managers who will be responsible for criterion collection. Predictive validity for the interview can be demonstrated if the interviewers and managers are both trained in making careful ratings of applicant/employee effectiveness and if the time for criterion collection is limited to the end of the probationary period.

\section{REFERENCE NOTE}

1. Wherry, R. J. The control of bias in ratings: VII. A theory of rating (Department of the Army, Project No. 29545100, Subtask 75, Subproject 9, Personnel Research Report No. 922). Columbus, Ohio: Ohio State University Research Foundation, February 1952.

\section{REFERENCES}

Bass, B. M., \& Vaughan, J. A. Training in industry: The management of learning. Belmont, Calif: Wadsworth, 1966.

Bellows, R. M., \& Estep, M. F. Employment psychology: The interview. New York: Rinehard, 1954.

Blum, M. L., \& NaYlor, J. C. Industrial psychology: Its theoretical and social foundations. New York: Harper \& Row, 1968.

Bruner, J. S. On perceptual readiness. Psychological Review, $1957,64,123-152$.

Campbell, D. T., \& Stanley, J. C. Experimental and quasiexperimental designs for research. Chicago: Rand McNally, 1963.

Cronbach, L. J. Essentials of psychological testing. New York: Harper \& Row, 1970

Dictionary of Occupational Titles (3rd ed.). Washington, D.C: U.S. Department of Labor, 1965.

Hakel, M. D., \& Schun, A. J. Job applicant attributes judged important across seven diverse occupations. Personnel Psychology, 1971, 24, 45-52.

KaHn, R. L., \& CANNell, C. F. The dynamics of interviewing: Theory, techniques, and cases. New York: Wiley, 1957.

MAYFIELD, E. C. The selection interview: A re-evaluation of published research. Personnel Psychology, 1964, 17, 239-260.

Scнuн, A. J. Effects of employment interviewing training on perceptions of a job applicant. Unpublished doctoral dissertation, Ohio State University, 1971.

Schur, A. J. Effects of interview rating form content and rater experience on the evaluation of a job applicant. Personnel Psychology, 1973, 26, 251-260.

Spool, M. D. Training programs for observers of behavior: A review. Personnel Psychology, 1978, 31, 853-888.

Uhrb rock, R. J. The personnel interview. Personnel Psychology, 1948, 1, 273-302.

UlRich, L., \& Trumbo, D. The selection interview since 1949. Psychological Bulletin, 1965, 63, 100-116.

WAgNer, R. The employment interview: A critical review. Personnel Psychology, 1949, 17, 239-260.

WEBSTER, E. C. Decision making in the employment interview. Montreal: Eagle, 1964.

Whisler, T. L., \& HARper, S. F. (Eds.). Performance appraisal: Research and practice. New York: Holt, Rinehart, \& Winston, 1962.

Wonderlic, E. F. Improving interview techniques. Personnel, $1942,18,232-238$.

WRIGHT, O. R. Summary of research on the selection interview since 1964. Personnel Psychology, 1969, 22, 391-413.

(Received for publication March 10, 1981.) 